Original Research Paper

\title{
Pendampingan Masyarakat dalam Pengolahan Kotoran Ternak Menjadi Kompos untuk Meningkatkan Pertumbuhan Tanaman
}

\author{
Ahmad Raksun $^{1 *}$, Wayan Merta ${ }^{1}$, I Gde Mertha ${ }^{1}$ \\ ${ }^{\text {I} P r o g r a m ~ S t u d i ~ P e n d i d i k a n ~ B i o l o g i, ~ F a k u l t a s ~ K e g u r u a n ~ d a n ~ I l m u ~ P e n d i d i k a n, ~ U n i v e r s i t a s ~ M a t a r a m, ~ M a t a r a m, ~ I n d o n e s i a ~}$
}

https://doi.org/10.29303/jpmpi.v3i2.858

Sitasi: Raksun, A., Merta, W., \& Mertha, I. G. (2021). Pendampingan Masyarakat dalam Pengolahan Kotoran Ternak Menjadi Kompos untuk Meningkatkan Pertumbuhan Tanaman. Jurnal Pengabdian Magister Pendidikan IPA, 4(3)

Article history

Received: 05 Juli 2021

Revised: 19 Juli 2020

Accepted: 30 Juli 2021

*Corresponding Author:

Ahmad Raksun, Program Studi Pendidikan Biologi, Fakultas

Keguruan dan Ilmu Pendidikan, Universitas Mataram, Mataram, Indonesia;

Email:

ahmadunram@unram.ac.id

\begin{abstract}
Kegiatan pengabdian kepada masyarakat ini telah dilaksanakan di Dusun Presak Desa Terong Tawah Kecamatan Labuapi Kabupaten Lombok Barat. Masalah utama yang dihadapi mitra adalah: (1) mitra belum menemukan alternatif pemecahan masalah kotoran ternak yang dihasilkan dari kegiatan peternakan, (2) mitra tidak memiliki pengetahuan tentang teknik pemupukan tanaman menggunakan kompos. Solusi untuk mengatasi masalah pertama adalah dengan mengolah kotoran ternak menjadi kompos. Untuk mengatasi masalah kedua maka tim melakukan pendampingan kepada mitra dalam melakukan pemupukan tanaman budidaya menggunakan kompos. Pelaksanaan kegiatan dilakukan dengan metode ceramah, tanya jawab dan pendampingan. Setelah berakhirnya kegiatan ini, mitra memiliki pengetahuan dan keterampilan tentang teknik pengolahan kotoran ternak menjadi kompos. Mitra memiliki pengetahuan dan keterampilan tentang teknik pemupukan tanaman menggunakan kompos dalam budidaya tanaman. Mitra kegiatan ini memiliki respons yang baik dan terlibat secara aktif selama pelaksanaan kegiatan.
\end{abstract}

Keywords: Pengolahan; Pengolahan kotoran ternak; Kompos; Pertumbuhan tanaman.

\section{Pendahuluan}

\section{dalam wilayah Desa Terong Tawah Kecamatan Labuapi Kabupaten Lombok Barat Provinsi Nusa Tenggara Barat. Masyarakat Dusun Presak Desa Terong Tawah Kecamatan Labuapi sebagian besar hidup sebagai petani dan sebagian kecil lainnya hidup sebagai pegawai negeri sipil, pedagang, buruh tani, tukang bangunan, penjahit, pedagang asongan dan peternak sapi atau kambing. Masyarakat Dusun Presak secara umum masih tergolong masyarakat dengan ekonomi lemah.}

Sebagian masyarakat Dusun Presak yang bermatapencaharian sebagai petani dan buruh tani memiliki usaha sampingan yaitu beternak sapi, kuda atau kambing. Ternak sapi, kuda dan kambing masyarakat tani Dusun Presak dipelihara dengan cara dikandangkan pada sebuah kandang kolektif. Peternak kuda memelihara kuda untuk digunakan sebagai penarik alat transportasi cidomo, sedangkan yang memelihara sapi dan kambing bertujuan untuk dikembangbiakkan. Setelah jumlah sapi dan kambing menjadi banyak maka sebagian akan dijual untuk memenuhi kebutuhan hidup seharihari. Kegiatan peternakan sapi, kuda dan kambing yang dilakukan oleh masyarakat tani Desa Terong Tawah menghasilkan kotoran ternak. Kotoran ternak biasanya dimusnahkan dengan cara dibuang ke kali sehingga berdampak negatif terhadap kebersihan air kali.

Masyarakat tani Dusun Presak Desa Terong Tawah memiliki penghasilan yang rendah. Hal ini disebabkan oleh minimnya hasil usaha pertanian yang mereka lakukan sebagai dampak dari rendahnya pengetahuan mereka khusus tentang 
teknik pemupukan tanaman. Selama ini masyarakat melakukan pemupukan tanaman menggunakan pupuk kimia sintetik seperti pupuk urea dan NPK. Penggunaan pupuk kimia sintetik secara terus menerus dalam waktu yang lama tanpa adanya penggunaan pupuk organik menyebabkan terjadinya degradasi fungsi lahan pertanian dan kebutuhan pupuk kimia makin lama makin tinggi. Zulkarnaen (2014) menjelaskan bahwa aplikasi input kimiawi yang berupa pupuk dan pestisida sintetik dengan dosis tinggi tidak hanya berpengaruh menurunkan tingkat kesuburan tanah, tetapi juga mengakibatkan pada merosotnya keanekaragaman hayati, meningkatnya serangan hama dan penyakit, timbulnya hama yang resisten dan berkembangnya organisme parasit. Selain itu dampak negatif dari penggunaan input kimiawi tidak hanya terbatas pada daerah pemakaian tetapi dapat menjadi makin luas melalui komponen rantai makanan seperti air minum, sayuran, buah- buahan dan produk-produk lain yang terkontaminasi.

Masyarakat peternak sapi, kuda dan kambing Dusun Presak Desa Terong tawah sampai saat ini belum menemukan alternatif pemecahan masalah kotoran ternak yang ada di lingkungan sekitar tempat tinggal mereka. Pengolahan kotoran ternak menjadi pupuk kompos merupakan alternatif pemecahan masalah yang dapat diterapkan untuk mengatasi permasalahan yang dihadapi oleh peternak sapi, kuda dan kambing Dusun Presak Desa Terong Tawah. Pupuk kompos yang dihasilkan dapat dijadikan pupuk pada lahan pertanian untuk mengurangi penggunaan pupuk kimia dan meningkatkan hasil panen tanaman. Hasil penelitian Lawenga dkk (2015) menunjukkan bahwa pemberian pupuk organik dapat memperbaiki sifat fisika tanah terutama pada bobot isi tanah, porositas dan permeabilitas. Demikian juga Nuro dkk (2016) menyimpulkan bahwa aplikasi pupuk organik berpengaruh terhadap sifat kimia tanah dan produksi kangkung darat. Pemanfaatan kompos atau pupuk organik pada lahan pertanian berdampak positif terhadap ketersedian hara, pertumbuhan dan produksi tanaman. Hasil penelitian yang dilakukan oleh Indriyati (2005) menunjukkan bahwa pemberian pupuk kompos mampu meningkatkan pertumbuhan dan produksi padi di lahan pasang surut sulfat masam. Perlakuan kompos feses sapi berpengaruh nyata terhadap peningkatan tinggi batang, panjang daun dan berat basah buah terong hijau (Raksun et al, 2021). Pemberian kompos berpengaruh nyata terhadap tinggi tanaman, umur berbunga, umur panen dan berat buah cabai rawit (Maruli et al, 2012). Pemberian kompos berpengaruh nyata terhadap tinggi tanaman, panjang daun, lebar daun, diameter batang, waktu muncul bunga jantan dan bunga betina, panjang tongkol dan jumlah biji tanaman jagung manis (Syafriliandi et al, 2016). Dosis kompos berpengaruh nyata terhadap panjang buah dan berat basah buah cabai rawit. Dosis kompos optimum adalah 1,6 - $2 \mathrm{~kg}$ kompos per 1 m2 lahan pertanian (Raksun, et al 2019)

Berdasarkan uraian di atas maka kami tim pelaksana pengabdian kepada masyarakat Universitas Mataram, berupaya menjadikan masyarakat peternak sapi, kuda dan kambing Dusun Peresak Desa Terong Tawah sebagai mitra pelaksanaan pengabdian kepada masyarakat. Ada dua permasalahan utama yang dihadapi oleh mitra, yaitu: (1) mitra belum menemukan alternatif pemecahan masalah kotoran ternak yang dihasilkan dari kegiatan peternakan, (2) mitra tidak memiliki pengetahuan tentang teknik pemupukan tanaman menggunakan kompos.

\section{Metode}

Kotoran ternak yang dihasilkan dari kegiatan peternakan sapi, kuda dan kambing di Dusun Presak Desa Terong Tawah dijadikan bahan baku pembuatan kompos. Pembuatan kompos. Kegiatan ini dilakukan dengan menggunakan metode ceramah, diskusi, pelatihan dan pendampingan. Adapun tahapan kerja pengolahan koran ternak menjadi kompos dan penggunaannya sebagai pupuk untuk meningkatkan pertumbuhan tanaman adalah sebagai berikut: (1) Persiapan, pada tahap persiapan dilakukan diskusi internal tim pelaksana pengabdian serta mengumpulkan alat dan bahan yang diperlukan, (2) Sosialisasi, kegiatan sosialisasi dilakukan kepada mitra menggunakan metode ceramah dan tanya jawab. Pada saat sosialisasi, tim pelaksana menyampaikan maksud dan tujuan pelaksanaan kegiatan kepada masyarakat, (3) Pengolahan kotoran ternak menjadi kompos. Alat yang digunakan dalam pembuatan kompos adalah cangkul, sekop, terpal, gentong air, ember, artco dorong dan karung nilon. Bahan yang digunakan adalah kotoran ternak, air, dedak, sekam dan kompos, (4) Penggunaan kompos untuk meningkatkan pertumbuhan tanaman, dilakukan dengan metode pendampingan. Tanaman uji coba 
penggunaan kompos adalah jagung manis dan sawi. Lahan pertanian (sawah) yang sudah diolah, dibuat bedengan dengan lebar $90 \mathrm{~cm}$ dan panjang 12 meter. Pada bedengan lahan tersebut diberikan kompos 14 hari sebelum ditanami jagung manis dan sawi.

\section{Hasil dan Pembahasan}

Dalam kegiatan pengabdian kepada masyarakat ini ada dua permasalahan utama yang dihadapi oleh kelompok masyarakat yang menjadi mitra kegiatan, yaitu: (1) mitra belum menemukan alternatif pemecahan masalah kotoran ternak yang dihasilkan dari kegiatan peternakan, (2) mitra tidak memiliki pengetahuan dan keterampilan tentang teknik pemupukan tanaman menggunakan kompos. Solusi yang dilakukan dalam upaya mengatasi permasalahan pertama adalah dengan mengolah sampah peternakan menjadi kompos. Kompos adalah pupuk yang berasal dari sisa-sisa tanaman yang dibusukkan melalui proses dekomposisi (Djuarnani dkk, 2005). Pengolahan sampah peternakan menjadi pupuk organic kompos, menjadikan lingkungan sekitar Dusun Presak Desa Terong Tawah menjadi bersih dari sampah peternakan. Selain itu kompos yang dihasilkan dapat digunakan untuk memupuk tanaman. Untuk mengatasi masalah kedua maka tim memberikan solusi dengan melakukan pendampingan kepada masyarakat dalam pemupukan tanaman khususnya dalam pemupukan tanaman menggunakan kompos. Tanaman yang dibudidayakan mitra adalah jagung manis dan tanaman sawi.

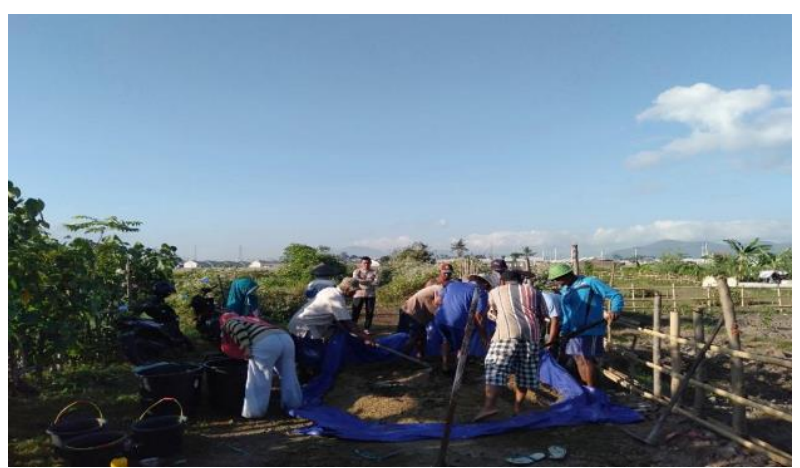

Gambar 1. Pembuatan Pupuk Kompos oleh Mitra

Pengolahan sampah peternakan menjadi kompos, dijadikan alternatif pemecahan masalah mitra yang dilakukan tim pelaksana pengabdian pada masyarakat mengacu pada hasil penelitian yang sudah dilakukan oleh tim pelaksana dan peneliti-peneliti yang lain. Hasil penelitian yang sudah dilakukan oleh Raksun et al (2018) menyimpulkan bahwa penggunaan kompos pada lahan pertanian Desa Sukarara berpengaruh nyata terhadap panjang batang dan jumlah anak daun kacang panjang. Dosis optimum kompos yang perlu diberikan pada lahan pertanian Desa Sukarara agar kacang panjang dapat tumbuh secara optimal adalah 2,0 $\mathrm{kg}$ kompos untuk $1 \mathrm{~m}^{2}$ lahan pertanian. Selanjutnya Raksun et al (2019) menemukan bahwa dosis kompos berpengaruh sangat nyata terhadap panjang buah dan berat basah buah cabai rawit, dosis kompos optimum untuk tanaman cabai rawit adalah 1,6-2 kg kompos per $1 \mathrm{~m} 2$ lahan pertanian. Perbedaan dosis kompos berpengaruh nyata terhadap tinggi batang, panjang helaian daun dan lebar helaian daun kangkung darat tetapi tidak berpengaruh nyata terhadap jumlah daun kangkung darat. Perbedaan waktu pemberian kompos berpengaruh nyata terhadap semua parameter pertumbuhan yang diukur. Interaksi antara dosis dan waktu pemberian kompos berpengaruh nyata terhadap jumlah daun dan panjang helaian daun tetapi tidak berpengaruh nyata terhadap tinggi batang dan lebar helaian. daun kangkung darat. Dosis optimum kompos yang perlu diberikan pada lahan pertanian Desa Bajur Kecamatan Labuapi agar kangkung darat dapat tumbuh optimal adalh 1,5 kg per $1 \mathrm{~m} 2$ lahan (Raksun et al, 2020).

Dalam kegiatan pengabdian kepada masyarakat ini, kompos yang diproduksi oleh mitra digunakan untuk memupuk tanaman. Adapun tanaman yang dipupuk dengan kompos pada kegiatan ini adalah, tanaman jagung manis dan tanaman sawi. Penggunaan pupuk kompos tersebut dapat mengurangi penggunaan pupuk kimia untuk meningkatkan pertumbuhan tanaman. Lahan pertanian diberikan kompos sebanyak $1,8 \mathrm{~kg}$ per $\mathrm{m}^{2}$ lahan. 


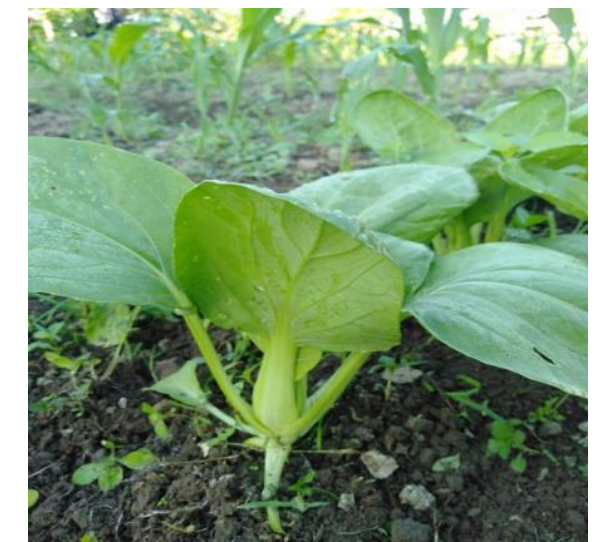

Gambar 2. Tanaman sawi yang dipupuk dengan kompos

Kegiatan pengabdian kepada masyarakat ini berlangsung dengan baik. Masyarakat yang menjadi mitra kegiatan telah mengikuti kegiatan dengan baik mulai dari sosialisasi kegiatan sampai pada saat pelaksanaan pembuatan kompos dan penggunaan kompos pada lahan pertanian. Hal ini dapat dilihat dari banyaknya pertanyaan yang diajukan peserta yang terkait dengan materi yang disampaikan tim pelaksana pada saat diskusi. Selain itu pada saat praktek pembuatan kompos semua peserta ikut bekerja secara aktif sehingga kegiatan praktek pembuatan kompos dapat berjalan sesuai dengan jadwal yang telah ditetapkan.

Pelaksanaan kegiatan pengabdian seperti ini sangat penting artinya bagi masyarakat mitra karena melalui kegiatan ini mereka dapat memahami berbagai dampak yang mungkin timbul sebagai akibat banyaknya sampah kotoran ternak yang dihasilkan dari kegiatan peternakan sapi, kuda dan kambing. Selanjutnya mereka diharapkan dapat melakukan pencegahan terhadap timbulnya dampak tersebut dengan tidak membuang sampah disembarang tempat dan memanfaatkan sampah organik kotoran sapi, kuda dan kambing sebagai bahan baku pembuatan kompos untuk meningkatkan pertumbuhan tanaman yang dibudidayakan di lahan persawahan maupun di pekarangan rumah.

Kompos yang dibuat mitra memerlukan waktu 10 minggu. Setelah selesai pembuatan kompos dengan bahan baku kotoran ternak, kegiatan dilanjutkan dengan penggunaan kompos sebagai pupuk pada lahan pertanian untuk meningkatkan pertumbuhan tanaman dengan langkah kerja sebagai berikut: (1) langkah pertama adalah pembuatan kompos oleh mitra, (2) pembuatan bedengan pada lahan yang akan ditanami tanaman jagung manis dan sawi, (3) aplikasi kompos pada bedengan dengan dosis 1,8 $\mathrm{kg}$ bokashi per $1 \mathrm{~m}^{2}$ lahan pertanian, (4) mencampur tanah pada bedengan dongan kompos sampai tercampur secara merata, (5) Membiarkan kompos dan tanah bercampur selama 2 minggu, (6) penanaman benih jagung manis dan sawi, (7) melakukan pemeliharaan tanaman jagung manis dan sawi yang meliputi pengairan, penyiangan dan pemberantasan hama dan penyakit tanaman.

Mitra pelaksanaan kegiatan pengabdian memiliki keinginan yang kuat untuk mengatasi masalah sampah peternakan yang ada disekitar tempat tinggal mereka. Kondisi tersebut merupakan faktor pendorong bagi peserta dalam mengikuti kegiatan ini. Melalui kegiatan ini, mereka memahami dan menyadari bahwa jika sampah yang mereka hasilkan dibuang di sembarang tempat dapat menimbulkan berbagai dampak negatif bagi lingkungan. Dengan demikian mereka memiliki keinginan yang kuat untuk menjadi peserta kegiatan ini dan memanfaatkan sampah khususnya kotoran sapi, kuda dan kambing yang ada disekitar tempat tinggal mereka sebagai bahan baku pembuatan kompos serta memanfaatkan kompos untuk meningkatkan pertumbuhan tanaman pada lahan pertanian yang mereka miliki. Selain itu pengolahan sampah kotoran sapi, kuda dan kambing menjadi bokashi dapat meningkatkan kebersihan lingkungan.

Faktor penghambat pelaksanaan kegiatan pengabdian kepada masyarakat ini adalah banyak kegiatan di kampus sehingga tim pelaksana mengalami kesulitan dalam menentukan jadwal pelaksanaan pengabdian. Sementara itu masyarakat mitra juga memiliki kegiatan rutin seperti mengolah lahan pertanian, mencari makanan ternak dan kegiatan-kegiatan lainnya Kondisi tersebut menyebabkan tim pelaksana merasa kesulitan dalam menentukan waktu pelaksanaan kegiatan. Tim pengabdian masyarakat harus mengatasi hambatan tersebut dengan cermat agar waktu pelaksanaan kegiatan pengabdian tidak berbenturan dengan waktu perkuliahan di Universitas Mataram. Faktor penghambat lainnya adalah kurangnya air yang tersedia untuk mengairi lahan pertanian pada saat penanaman tanaman jagung manis dan tanaman sawi, karena kegiatan pengabdian ini dilakukan pada musim kemarau. Hambatan ini dapat diatasi dengan menyewa mesin pompa air untuk memompa air yang ada pada sumur di sekitar 
lahan pertanian yang dijadikan sebagai lahan penanaman tanaman uji coba penggunaan kompos.

\section{Kesimpulan}

Berdasarkan hasil pelaksanaan kegiatan yang meliputi kegiatan penyampaian materi, praktek pembuatan kompos, penggunaan kompos untuk meningkatkan pertumbuhan tanaman sampai dengan akhir pelaksanaan kegiatan maka dapat disimpulkan bahwa: (1) melalui pelaksanaan kegiatan ini, masyarakat Dusun Presak Desa Terong Tawah Kecamatan Labuapi Kabupaten Lombok Barat yang menjadi mitra kegiatan ini memiliki pengetahuan dan keterampilan tentang teknik pengolahan sampah organik menjadi kompos, (2) mitra kegiatan pengabdian pada masyarakat ini memiliki pengetahuan dan keterampilan tentang teknik pemupukan tanaman menggunakan kompos, (3) mitra kegiatan ini memiliki respons yang baik terhadap pelaksanaan kegiatan dan berkomitmen untuk mencoba memanfaatkan limbah yang dihasilkan dari usaha peternakan yang ada disekitar tempat tinggal mereka sebagai bahan baku pembuatan kompos. Selanjutnya menggunakan kompos untuk meningkatkan hasil panen tanaman yang ada di pekarangan maupun pada lahan persawahan yang mereka miliki.

\section{Ucapan Terima Kasih}

Termakasih yang sebesar-besarnya kami sampaikan kepada Rektor Universitas Mataram yang telah memfasilitasi penyediaan dana pelaksanaan pengabdian pada masyarakat. Terimakasih juga kami sampaikan kepada Ketua LPPM Universitas Mataram dan semua pihak yang telah membantu pelaksanaan pengabdian pada masyarakat ini.

\section{Daftar Pustaka}

Djuarnani, N., Darmanti, Marvelia, A., Sarjana,P. 2005. Cara Cepat Membuat Kompos. Agromedia Pustaka. Jakarta

Indrayati, L. 2005. Pengolahan Jerami Padi pada Pertanaman Padi Lahan Pasang Surut Sulfat Masam. Abstrak Hasil Penelitian Pertanian Indonesia Pusat Perpustakaan dan Penyebaran Hasil Penelitian Indonesia. Vol. XII No.2. Bogor.
Lawenga, F.F., U. Hasanah dan D. Widjajanto. 2015. Pengaruh Pemberian Pupuk Organik terhadap Sifat Fisika Tanah dan Hasil Tanaman Tomat (Lycopersicum esculentum Mill.) di Desa Bolupuontu Kecamatan Sigi Biromaru Kabupaten Sigi. Agrotekbis Vol. 3 (5): 564 570.

Maruli, Ernita dan Gultom, H. 2012. Pengaruh Pemberian NPK Grower dan Kompos terhadap Pertumbuhan dan Produksi Tanaman Cabai Rawit (Capsicum frustencen L.). Dinamika Pertanian. 27 (3): $149-155$

Nuro, F., D, Priyadi dan E.S. Mulyaningsih. 2016. Efek Pupuk Organik terhadap Sifat Kimia Tanah dan Produksi Kangkung Darat (Ipomoea reptans Poir). Proseding Seminar Nasional Hasil-Hasil Penelitian IPB. ISBN: 978-602-8853-29-3. Halaman $29-39$

Raksun, A. Mahrus dan Mertha, I.G. 2021. Effect of Urea and Cow Fecal Commpost on Growth and Yield of Green Eggplat (Solanum melongena, L.). Jurnal Penelitian Pendidikan IPA. 7 (1): $54-59$.

Raksun, A. Mahrus dan Mertha, I.G. 2021. Effect of Urea and Cow Fecal Commpost on Growth and Yield of Green Eggplat (Solanum melongena, L.). Jurnal Penelitian Pendidikan IPA. 7 (1): $54-59$

Raksun, A., Japa, L dan Mertha I.G. 2018. Pengaruh Kompos kotoran Kuda terhadap pertumbuhan Kacang Panjang. Biologi Tropis. Vol. 18 (2): $170-173$

Raksun, A., Mahrus dan Mertha, I.G. 2019. Pengaruh Jenis Mulsa dan Dosis Kompos terhadap Hasil Panen cabai rawit (Capsicum frutescens $\mathrm{L}_{\text {.) }}$. Pijar MIPA. Vol. 15 (1): 65 - 68

Raksun, A., Zulkifli, L. dan Mahrus. 2020. Pengaruh Dosis dan Waktu pemberian Kompos terhadap Pertumbuhan Kangkung Darat. Pijar MIPA. Vol. 15 (2): 171 - 176

Syafriliandi, Murniati dan Idwar. 2016. Pengaruh Jenis Kompos terhadap Pertumbuhan dan Produksi Tanaman Jagung Manis. Jom Faperta. 3 (2): 1 $-9$

Zulkarnain. H. 2014. Dasar-Dasar Hortikultura. Bumi Aksara. Jakarta. 